\title{
The Effect of Teaching Collocations on the Students'
}

\section{Perceptions toward Language Learning}

\author{
Kun-huei $\mathrm{Wu}^{1 *}$ \\ ${ }^{1}$ English Department, Aletheia University, Taiwan \\ *Kun-huei Wu, E-mail: au4284@mail.au.edu.tw
}

\begin{abstract}
Knowledge of collocation is fundamental for both receptive and productive use of the language. Collocation is often regarded as insurmountable obstacle to the attainment of native-like fluency. In other words, collocation skill has often been used to differentiate native and non-native speakers. The aim of this study is to investigate the effect of teaching collocation on the students' attitudes toward language learning in the classroom. To enhance both oral reading and speaking fluency, the researcher uses the repeated reading method to check the participants' productive performance. In addition, the participants are introduced and taught to use the online language database during the learning process. The results indicate that the participants hold positive attitudes toward the explicit teaching of collocations. The analyzed data reveal that the participants' language performance has been siginificantly affected by the instruction of collocations. The participants also express that they feel more confident and motivated to acquire accurate and native-like competence.
\end{abstract}

\section{Keywords}

collocation, repeated reading, CLT, DDL, concordance, corpus

\section{Introduction}

In the 1950s and 1960s, the grammar-translation and audio-lingual methods of language teaching prevail; however, the premium put on spoken communicative competence attracts more and more attention in the 1970s. It is one of the main goals for EFL students to become fluent speakers in the target language. Fluency has therefore become an important part in the learning of foreign language. Samules (1974) indicates that fluency contains two major components: word recognition and reading speed. In other words, the language learners are expected to decode and comprehend a text simultaneously and/or automatically. The method of repeated reading (RR) is a feasible way to help students to develop their fluency. Samules (1979) defines RR as “a supplement reading program that consists of re-reading a short and meaningful passage until a satisfactory level of fluency is reached” (p. 404). It is important for the teacher to select a suitable teaching material to develop the students' oral proficiency. The teaching material should be student-oriented, which is based on their level difference. Collocation proficiency has been seen as one of the ways that differentiates native and non-native 
speakers (Ellis, 2001; Koya, 2006; McCarthy, 2004a; Nation, 2001; Wouden, 1997). If someone says I did a few mistakes they will be understood, whereas a fluent speaker of English will say I made a few mistakes. Why do we say fast food instead of quick food? The reason is collocation. Learning collocations is a good idea because they can give the learners the most natural way to say something; for example, we would say that smoking is strictly forbidden rather than smoking is strongly forbidden. It is very important for the learners, when learning a new word, to pay attention to its dictionary definition as well as the type of words with which it is often associated. In addition, learning collocations will offer the learners alternative ways of saying something, which may be more colorful or more precise. For instance, we may say that it was bitterly cold and pitch dark, instead of repeating it was very cold and very dark. Also, learning collocations could improve the writing style. Instead of saying a big meal, we can say a substantial meal. A collocation is a pair or group of words that are often used together. Collocations, either fixed or more flexible, are the result of many years of habitual use by fluent speakers of English. These combinations sound natural to native speakers, but students of English have to make a special effort to learn them because they are often difficult to guess. English contains a plethora of collocations, recurrent combinations of words that co-occur more often than expected by chance. Some combinations just sound wrong to native speakers of English. For example, the adjective fast collocates with cars, but not with a glance. It is generally accepted that automation of collocations helps native speakers to express themselves fluently. Since native speakers have a good command of 'chunks' of English that are ready to use. Ur (1996) points out that vocabulary can be defined, roughly, as the words we teach in the foreign language. However, a new item of vocabulary may be more than a single word: for example, post office and mother-in-law, which are made up of two or three words but express a single idea. If learners lack collocation knowledge, they soon discover that their ability to comprehend or express themselves clearly is limited (Decarrico, 2001). To achieve native-like fluency, learners should be made aware of the fact that an important part of language acquisition is the learning of collocation. The aim of this study is to explore the effect of collocation teaching on the students' language performance. In addition, the researcher intends to discuss the students' perception toward collocation learning through in-depth interview.

\section{Definition of Collocation}

Firth (1957) first introduces the term "collocation" as "collocations of a given word are statements of habitual or customary places of that word."He indicates that words obtain their meaning from their co-occurrence in texts. It is commonly asserted that knowing a word includes knowing what words can occur with it or "the company it keeps" in order to use it both receptively and productively. Using collocations accurately is important in order to produce language with native-like accuracy or near-native competence. Based on the notion about collocation, subsequent researches related to collocation have appeared. Collocations include what have traditionally been considered lexical items, as well as structural patterns which may seem closer to grammar and combinations of words that 
simply go together. Generally, there are two different views about this term. One of them states that collocation is related to meaning; the other argues that collocation is not a semantic relation between words (Bahns, 1993). According to Benson et al. (1986a), collocation can be sorted systematically into two major groups-lexical collocations and grammatical collocations. A lexical collocation could be made up of nouns, adjectives, verbs, or adverbs. A grammatical collocation is made up of a dominant word and a preposition or grammatical structure like an infinitive or a clause. McIntosh (2009) points out the fact that words have only a certain tolerance of compatibility. Such knowledge of ranges helps to draw a line between the acceptable collocations and unacceptable collocations. Lewis (2000) states that the restrictions on how words can be used together or the way words naturally co-occur can be referred to as collocation. Similar to McIntosh, Bolinger and Sears (1981) also mention that collocation is a kind of habitual association of words. For example, the collocations like fast food, fast car, might be considered acceptable; on the contrary, the collocations like fast glance, fast look, unacceptable. Once learners have gained control of the most common words in English, without which efficient communication and independent use of the language is very difficult, the vocabulary learning task becomes more challenging. It is impossible for teachers to teach students all the English words. Unlike grammar teaching, where the teacher can push learners to a level where they have encountered and practiced all but the most obscure structures and patterns. In the case of many new words will be encountered just once, which is hardly enough to learn all you need to know about them. Therefore, the teaching and learning of vocabulary should be shifted from the "breadth" to "depth". In other words, the method of learning will be changed from "how many words you know" to "what you know about those words and how to use them." Students will still learn new words, but they'll also start to focus more on a special area such as collocation. It is generally accepted that collocation remains a challenge in learning any language. Fortunately, with the development of technology, students are no longer confined to classroom language but can now have access to language corpora or vast databases of authentic texts stored on computers or on the Internet. Using a corpus in the classroom is a good way to help the students achieve collocation awareness and accuracy as quickly and efficiently as possible.

\section{Repeated Reading Method}

Repeated reading (RR) is one of the ways that helps non-fluent readers to achieve automatic word identification skills. It focuses on improving the students' oral reading fluency. Samuels (1979) suggests that RR is an effective practice for increasing students' reading fluency. He further proposes that RR is the most used universal remedial technique to help poor readers and now also is broadly used for foreign language teaching. Dowhower (1987) suggests that the objective of RR is to re-read a meaningful passage until oral production is fluid and facile. One of the most important goals of RR is to reach automaticity - the skill level at which a complex cognitive task has become learned to the extent that very little effort or thought is required to perform the task. In their automaticity theory, LaBerge and Samuels (1974) define "automaticity" as the ability to read words quickly and 
automatically. Samuels (1979) compares RR to sports and music practice. "Sports and music require moves that must be made rapidly and automatically. The musician is faced with a text comprised of notes. The goal is not the mechanical rendition of sounds indicated by notes, but rather the rendering of those printed notes with fluency and expression. Decoding must be done automatically so the mind of the musician is free to play the score with emotion and feeling. What repeated reading does is to give the students the opportunity to master the material before moving on” (pp. 380-381). Oral reading fluency not only has to do with students' silent reading in English, but also is associated with their speaking abilities. Fluency is a commonly used notion in the teaching of language, frequently contrasted with accuracy especially in a communicative language teaching (CLT). CLT is arguably today's most popular teaching method in the field of English Language Teaching (ELT). Although the voice of using the innovative teaching approach becomes louder, the difficulties of the implementation should not be overestimated in the EFL context, such as the students' low proficiency, lack of teaching materials, and lack of cross-cultural understanding, etc. Under this circumstance, adequate teaching material for lower level students and teaching method should be taken into consideration. Young and Bowers (1995) suggest instructional practice of using materials that can be read accurately as the basis for fluency training. The researcher of the present study will use "English Collocations in Use" as the teaching material, which is written by Michael McCarthy and Felicity O'Dell. The theme-based texts are very practical and useful for EFL learners. As Hill (2000) observes, problematic expressions made by non-native speakers are "not because of faulty grammar but a lack of collocations.”The researcher of this study compares collocations to music notes, and intends to train the students to automatically speak out collocations just like the musician plays the notes. Repeated reading is an instructional method that incorporates the practice of orally re-reading a short passage to gain fluency as measured by the students' reading rate. Rate is measured by checking the students' oral readings for their correct words read per minute. In the present study, the researcher will explain and read a short passage first, then the students are asked to practice for five minutes; afterwards, each student's oral practice will be recorded. The researcher will play the recorded audio-track and ask the students to assess their own performance in fluency and accuracy. Lewis (2000) encourages teachers to raise students' awareness of collocations and to initiate their own action research to make sure the changes they make are of benefit to students. The objective of this study is to explore the students' perceptions toward the correlation between the collocation teaching and language performance through action research.

\section{The Research Question}

Cowie (1992) asserts that collocation is important in receptive as well as productive language competence. Carter and McCarthy (1988) point out that the students would have the idea about certain lexical restrictions by memorizing collocation groups. Liu (2000a) also claims that the more often students are taught English collocations, the more correctly students can make use of collocations. To facilitate the students' learning, Carter and McCarthy (1988) state that students will not have to go 
about reconstructing the language each time they want to say something but instead can use these collocations as pre-packed building blocks. The selected textbook English Collocations in Use is appropriate for learners from elementary to intermediate levels due to its breadth and depth, providing the learners with pre-packed materials. With the progress of language database, corpus has become a powerful tool for the learners. Unfortunately, students in the EFL context pay little attention to this useful tool when learning a language. In light of this circumstance, the researcher intends to discuss the following questions:

1) What are the participants' perceptions toward the teaching and learning of collocation?

2) What is the effect of using online language database on teaching collocation and the participants' language performance?

\section{The Participants}

Convenience sampling is used to select participants based on the availability of respondents. There are twenty students in my reading class, including 14 females and 6 males. They attend evening program, since they have full-time or part-time jobs during the daytime. They all agree to take part in the present study. To understand the students' English level, the researcher administers a placement test at the first class. The GEPT test (General English Proficient Test) was developed by The Language Training and Testing Center (LTTC), targets English learners at all levels in Taiwan. This test corresponds to Taiwan's English education framework, meets the specific needs of English learners in Taiwan for self-assessment, and provides institutions or schools with a reference for evaluating the English proficiency levels of their job applicants, employees, or students. The GEPT consists of five levels: elementary, intermediate, high-intermediate, advanced, and superior. The result of the test shows that only three of the students reach the intermediate level and the rest elementary (Table 1). Overall the participants' language proficiency is below the intermediate level. In the third week, the participants are divided into five small groups for in-class activities; each group has four members. The participants select their own partners.

Table 1.The participants' GEPT scores

\begin{tabular}{llllll}
\hline Level & elementary & intermediate & High-intermediate & advanced & superior \\
\hline male & $\mathrm{N}=5$ & $\mathrm{~N}=1$ & $\mathrm{~N}=0$ & $\mathrm{~N}=0$ & $\mathrm{~N}=0$ \\
female & $\mathrm{N}=12$ & $\mathrm{~N}=2$ & $\mathrm{~N}=0$ & $\mathrm{~N}=0$ & $\mathrm{~N}=0$ \\
\hline
\end{tabular}

\section{The Instrument}

The current study primarily involves a survey, through its standardized and structured design, aimed at identifying and comparing the effect of collocation instruction on learners' perceptions and attitudes toward language learning. The researcher reviews available theories related to teachers' and students' 
attitudes (Ajzen, 2005; Nunan, 1988) to lay out a conceptual framework. In an attempt to identify the participants' perceptions toward collocation teaching and learning, a research instrument, The Questionnaire of Perception on Collocation Teaching \& Learning, was developed by the researcher. It is comprised of three categories, intending to understand the effectiveness of collocation teaching on the participants' language performance, the influence of using corpus, and the change of learning behavior before and after the collocation instruction in the classroom. In the questionnaire, the participants were asked to assess their beliefs about collocation teaching and learning on a five-point Likert scale ranging from 1 (strongly disagree) to 5 (strongly agree). Internal consistency was calculated for the participants' responses to the 15 items in the questionnaire, and a Cronbach alpha coefficient of .73 was obtained, which indicated that the participants tended to respond to the questionnaire with a relatively high level of consistency. Descriptive statistics such as means, and standard deviations were computed using SPSS. T-test was calculated to compare the similarities and differences between pre-survey and post-survey. Apart from the 15 items in the questionnaire, one open-ended question was added to the end: "What is the main problem during your previous experience in learning English?” The participants could respond to this question either in English or in Chinese; the data were transcribed, segmented, and analyzed as valuable additional source of information to supplement the questionnaire survey. In addition to quantitative analysis, the present research focuses more on the qualitative analysis. Dorynei (2007) points out that qualitative research has traditionally been seen as an effective way of exploring new, uncharted areas (p. 39). Since the focus is on individual experience, in-depth interview was used as the data collection method. All the interviews were voice-recorded with the participants' consent. After the questionnaire survey was completed, interview with each group for 30 minutes was conducted, enabling the participants to further clarify or explain their written statements. The date of interview was decided by each group. The interview session was semi-structured, focusing on the participants' previous experience in learning English. Major topics include their awareness of collocation learning and online language database. The following discussions and analysis were filtered through the systematic approaches, which include constant cross-comparisons within the data, follow-up verification with the participants, and data-based analysis. The researcher combines the participants' responses and then presents their thoughts in the passages. The researcher tries to identify important passages in which the participants expressed deep feelings and reflections, and then makes some conjectures about the uncertainties and explore them by asking relevant questions. Although data obtained from a questionnaire survey only provides indirect evidence of the students' perceptions, they can still serve to broaden our understanding of the correlation between language teaching strategies and the participants' language performance.

In addition to the questionnaire, the researcher designs a test specifically for the survey, consisting of 50 questions: 25 fill-in-the-blank questions and 25 multiple choice questions (See Appendix B). Two points for each question, thus, the full marks for the test is 100 . Forty percent of the questions are quoted from unit 1 to unit 14 in the textbook, English Collocations in Use, and the rest 60\% are from 
related reference books or collocation dictionary. The participants will do the pre-test on week 1 and the post-test on week 9. The 50 questions in pre- and post-test are of the same. The purposes of these two tests are: (1) to understand the participants' collocation knowledge, (2) to analyze the effect of the repeated reading method and online language database on their performance. They are allowed to use any available tools but textbook during the test. The time limit for the test is 50 minutes.

\section{The Procedure}

The current study adopts the Action Research approach, including three main parts: the pre-implementation phase, implementation phase, and the post-implementation phase. The researcher completes the case study in nine weeks, including (1) identification of problem area, (2) collection and organization of data, (3) interpretation of data, (4) action based on data, (5) reflection. The pre-implementation phase aims to give an orientation to the students about the importance of collocation knowledge in their language skills. Before the orientation starts, the researcher administers a pre-test on collocation, along with a questionnaire. The primary purpose of the pre-test is to understand the students' general knowledge on collocation and their perceptions toward collocation teaching. The main task in the pre-implementation phase is to explain in details to the students about the types of collocation, the causes of collocation errors, the criteria of choosing course book. In the pre-implementation phase, the researcher will spend two weeks (four hours in total, 2 hours per week) to ensure that every student has been clearly guided.

After two weeks, the researcher will continue the implementation phase from week 3 to week 6 . The primary task in this phase is to introduce the procedures to use a corpus. With the development of technology, the learning of language has become more and more convenient. Nowadays, technology has significantly affected the ways of learning. A variety of databases have been developed in diverse fields. The introduction of technology-supported learning tools into the language classroom has led to innovative changes. For language learners, they have access to language corpora, examine authentic language as well as discover linguistic patterns by themselves. The term DDL (data-driven learning) has first defined and presented by Johns (1991). He argues that learners should be guided to draw their own conclusions based on the corpus data. He also points out that DDL focuses on learner-centered activities, rather than traditional drill and kill exercises. In the light of this, there has emerged a general interactionist perspective proposing that interaction, interpersonal as well as intrapersonal, plays a major part in setting the stage for language acquisition to take place. In the implementation phase, the main tasks include group discussion, peer cooperation and assessment, and the shift from the teacher-centered teaching strategy to student-oriented learning model. There have been plentiful calls to use more group activities in the educational system and English Language Teaching (ELT) (Diller, 2007).The usefulness and benefits of group work in learning a language is widely recognized. In the present study, members of each group need to practice individually as well as cooperate with one another during the in-class activities. Repeated reading method is used to train every student to be 
familiar with the collocations in bold type in the sentences. For example, "weather deteriorate" should be automatically translated into the learners' mother language and vice versa. Then they have to read the sentence "The weather is likely to deteriorate later on today" for 5 times. Repeated reading method aims to train the learners to improve their reading speed, and express themselves fluently. Each of the participants will record the time his or her partner spent in reading a short passage. There are only two criteria during the self- and peer assessment activities: fluency and accuracy. The purpose of this activity is to train the participants to repeatedly input the prefabricated chunks till they can fluently use the collocations. After that, the researcher will introduce the online language database to the students: What is corpus? What is a concordance? What is concordancing? A corpus is a collection of sample texts in computer-readable form. The sample texts can come from any source in which the language is used in speech and in writing, such as newspapers, magazines, websites, journals, books, television and radio. A concordance is a set of examples of a given word or phrase, showing the context. Concordancing is accessing a corpus to learn the patterns in which a word or phrase is typically used. Each group will be assigned to practice the concordancing activity. As mentioned earlier, the application of language database will facilitate the learning process and help to raise the students' awareness of collocation knowledge. It is not difficult for students to acquaint themselves with the modern technology, but hard to motivate them in the traditional teaching context. With the assistance of scaffolding, the learners will be directed toward a more successful way in the learning of a foreign language. One of the most important tasks for the teacher is to introduce the available online resources and selects one of them as a demonstration sample. The primary objective during the implementation phase is to introduce to the students the know-how of concordancing.

The post-implementation phase (week 7 to week 9) will focus on post-test, data analysis and the participants' feedback, whose reflection and feedback will be seen as valuable reference regarding the efficacy of collocation teaching. The main tasks in pre-implementation, implementation and post-implementation phases are illustrated in Table 2.

Table 2. The tasks for three implementation phases

\begin{tabular}{|c|c|c|}
\hline & week & main task \\
\hline Pre-implementation phase & $1-2$ & $\begin{array}{l}\text { 1. Pre-test: a test on collocation \& questionnaire } \\
\text { 2. Orientation: what is collocation, types of collo }\end{array}$ \\
\hline Implementation phase & $3-6$ & $\begin{array}{l}\text { 1.Demonstrate how to use corpus, concordance } \\
\text { 2. Monitor peer assessment and group work }\end{array}$ \\
\hline Post-implementation phase & $7-9$ & $\begin{array}{l}\text { 1.Post-test: a test on collocation \& questionnaire } \\
\text { 2.Feedback, reflection, interview, data analysis }\end{array}$ \\
\hline
\end{tabular}

.Feedback, reflection, interview, data analysis 


\section{Results and Discussion}

The result of post-test scores on collocation indicates that the participants make improvement, compared to their previous performance (Table 3).

Table 3. The scores for pre- and post-test on collocations

\begin{tabular}{llllll}
\hline scores & $0-18$ & $20-38$ & $40-58$ & $60-78$ & $80-100$ \\
\hline Pre-test & $\mathrm{N}=8$ & $\mathrm{~N}=10$ & $\mathrm{~N}=2$ & $\mathrm{~N}=0$ & $\mathrm{~N}=0$ \\
Post-test & $\mathrm{N}=0$ & $\mathrm{~N}=5$ & $\mathrm{~N}=13$ & $\mathrm{~N}=2$ & $\mathrm{~N}=0$ \\
\hline
\end{tabular}

Regarding the improvement on collocation test, all the participants mention in the interviews that they benefit from the repeated reading method. Because they rarely use this method in the previous learning experience, the participants feel more confident after they receive such training. Although there are only 2 participants who get scores above 60, most of the participants value the usefulness of this method. This result implies that the repeated reading method has positive effect on their performance. Since the participants are asked to practice repeatedly in the classroom, they become more familiar with the $40 \%$ questions from the textbook. As to the other $60 \%$ questions, they still lack confidence due to their unfamiliarity with the language database and the time limit. In addition to their improvement on the collocation test, the participants also express their favorable responses in the questionnaire. The overall mean for the item responses in the pre-test questionnaire is 2.98 , but in the post-test, the mean scores increase from 2.98 to 4.12 (Table 4).

Table 4. The overall mean scores for pre- and post-survey questionnaire

\begin{tabular}{llll}
\hline & Mean & SD & $t$-value \\
\hline Pre-survey & 2.98 & 1.12 & $3.89 *$ \\
Post-survey & 4.12 & 0.76 & \\
\hline
\end{tabular}

Note. ${ }^{*} p<.01$.

According to the result of post-test questionnaire, the researcher observes that the participants hold very favorable attitudes toward the teaching and learning of collocation as well as language database. What are the factors of affecting the improvement on their collocation performance? What is the relationship between the learning of collocation and the students' fluency in reading and speaking? Do the participants feel more confident and become more autonomous after receiving the training of using corpus? Based on the result of questionnaire, along with the interviews with the participants, the researcher will discuss the participants' attitudes toward collocation learning, the teaching method, the teaching material, the learning tool, and the perception toward the teacher's role.

There are 15 items in the questionnaire. The first category refers to the general view on learning 
English vocabulary, chunks, collocation instruction. The results indicate that the participants change their perceptions as to vocabulary learning and collocation teaching (item $3, t(19)=4.19$; item 4 , $t(19)=3.98$; item $5, t(19)=4.56, p<.01)$. The second category is related to teaching approach, including the selection of textbook, the repeated reading method, and the functions of group activities. The result reveals that the participants hold very positive attitudes toward repeated reading method (item 7 , $t(19)=4.17, p<.01)$. The third category includes the benefits of using corpus; how does the technology-supported database facilitate the learning of the target language; what change has been made as to the teacher's role during the teaching process. As to the online language database, the results reveal that the participants show favorable attitudes (item 10, $t(19)=4.03$; item $11, t(19)=4.22$; item 12, $t(19)=4.31, p<.01)$. Regarding the teacher's role, the participants seem to have different perspectives (item 15, $t(19)=3.44, p<.01)$. The improvement of post-test scores on collocation indicates that the participants realize the importance of learning collocation, and they learn in a more beneficial way. According to Cowie (1992), English collocation is important in receptive as well as productive language competence. In the present study, the researcher designs this questionnaire to understand the participants' general perceptions toward the relationship between the instruction of collocation and their language performance. The results of means and standard deviations for the questionnaire are illustrated in Table 5.

Table 5. Means and standard deviations for the questionnaire

\begin{tabular}{lllllc}
\hline \multicolumn{2}{c}{ Item Description } & test & M & SD & $t$ \\
\hline 1. Language classes should be & pre- & 3.98 & 0.68 & 1.14 \\
student-centered, not teacher-centered & post & 4.19 & 0.54 & \\
2. Using English-English dictionary is very & pre- & 2.99 & 1.21 & 1.58 \\
important when learning a new word & post & 3.41 & 1.20 & \\
3. Chunks are important when learning & pre- & 2.34 & 0.65 & $4.19^{*}$ \\
English vocabulary & post & 4.15 & 0.70 & \\
4. Part of speech in English is important when & pre- & 2.74 & 0.83 & $3.98^{*}$ \\
learning a new word & post & 3.98 & 0.51 & \\
5. Collocation teaching is very helpful in & pre- & 2.11 & 0.77 & $4.56^{*}$ \\
language learning & post & 4.45 & 0.73 & \\
6. The selection of teaching material must be & pre- & 4.01 & 1.03 & 1.22 \\
based on learners' level & post & 4.31 & 0.87 & \\
7. Repeated reading method is helpful to & pre- & 2.34 & 1.21 & $4.17^{*}$ \\
improve learners' speaking ability & post & 4.02 & 0.98 & \\
8. Peer assessment develops oral & pre- & 3.22 & 0.70 & 1.61 \\
conversational skills in English & post & 3.99 & 1.03 & \\
\hline
\end{tabular}


9. Group work creates a motivating environment to use English

10. Corpus is a very powerful online language database when learning languages

11. Concordance is helpful when searching for information about a given word or phrase

12. Concordancing is beneficial to raise collocation awareness

13. Language learning should be more independent and autonomous

14. Language learning should be less threatening

15. Teacher correction should be provided only when it is required for effective communication

$\begin{array}{llll}\text { pre- } & 3.01 & 1.12 & 2.01 \\ \text { post } & 4.05 & 0.79 & \\ \text { pre- } & 2.98 & 1.14 & 4.03^{*} \\ \text { post } & 4.23 & 1.01 & \\ \text { pre- } & 2.15 & 0.98 & 4.22^{*} \\ \text { post } & 4.31 & 0.89 & \\ \text { Pre- } & 2.21 & 0.56 & 4.31^{*} \\ \text { post } & 4.39 & 0.97 & \\ \text { pre- } & 3.65 & 1.02 & 1.36 \\ \text { post } & 4.11 & 0.85 & \\ \text { pre- } & 4.11 & 0.84 & 1.01 \\ \text { post } & 4.22 & 0.95 & \\ \text { pre- } & 3.01 & 1.20 & 3.44^{*} \\ \text { post } & 3.99 & 1.04 & \\ & & & \end{array}$

Note. ${ }^{*} p<.01$

The participants show distinct attitudes before and after the learning of collocation. Regarding the importance of learning collocations, all the participants respond that they have no idea as to the term "collocation" till they take the researcher's reading course; they point out that they have similar problems in producing the correct collocation due to their lack of collocation concept. This problem seems to confuse them profoundly in their learning experience. Direct translation from their mother tongue would be used to be their solution. Thus, L1 interference is very common when producing the wrong or inappropriate collocation. For instance, the students may use learn knowledge rather than gain knowledge. To raise their awareness of collocation, the researcher explains the causes of collocational errors and gives them examples to make them understand about the possible errors they make. Recent experimental studies indicate that the causes of collocational errors are related to analogy, overgeneralization, paraphrase, the L1 interference, interlingual transfer, and shortage of collocation knowledge (Channell, 1981; Bahas, 1993; Bahns \& Eldaws, 1993; Farghal \& Obiedat, 1995; Liu, 2000a). The participants are strongly advised to pay attention to these causes of (mis)collocations. In the interviews, 8 participants from group 1 and group 2 state that they have better understanding about the causes of collocational errors as well as the concept of collocation.

Group 1: We have no idea about the term collocation until we take the course. We are very impressed by the teacher's way of comparison, in which the teacher compares collocations to our next-door neighbors. There are good neighbors and bad neighbors. Good neighbors are welcome and acceptable, however, bad neighbors unacceptable. In the past, when we learn a new English word, we seldom care which word goes with the word we try to learn. We usually focus on the Chinese meaning when we Published by SCHOLINK INC. 
don't understand the meaning of a new English word and check in the English-Chinese dictionary. Besides checking the Chinese meaning, we pay little attention to terms like definition, parts of speech, chunks, collocation, etc. In this reading course, the teacher asks us to rethink the steps to learn vocabulary. We are expected to follow the 5 steps: 1. to pronounce the new word properly 2.to say the word's definition in English 3.to identify the word's part of speech 4.to find the word's collocations 5. To make a meaningful sentence based on the word's collocation. In the previous learning experience, we just memorize the spelling and Chinese meaning of every new word for exam purpose. We are not particularly requested to pay attention to which word is acceptable or unacceptable to collocate with another word. We all agree that we lack concept like "chunk" in our learning experience. This concept seems to play a very important role in our speaking and writing. After nine weeks, we gradually feel that we have better understanding about the functions of collocation. But, we still need to spend more time and effort to improve our English proficiency (interviewees: Alice, Christine, Janet, Paul).

Group 2: Sometimes we are confused about learning English expression, for example, why do we say powerful engine, not strong engine; why do we use a quick meal, not a fast meal. In the reading course, we get the answer. It is collocation. The teacher tells us that collocation is a habitual combination used by native speakers. Honestly speaking, none of us has such concept till we take the course. From the beginning, the teacher tells us what is a collocation, and why do we need to learn collocations. The teacher shows us some examples that we already know, for example, make a mistake, make a decision, etc. A fluent speaker would not say do a decision, because it sounds unnatural. The teacher says that there are many different types of collocations, and he explains to us the six types of collocations in the textbook. The teacher teaches us how to find collocations, how to record collocations, and how to use collocations. Particularly, the teacher teaches us how to check collocations from the dictionary and language database. The learning resources are so useful and new to us. The teacher tells us that Rome was not built in a day, so we are advised to systematically input the collocations day by day. The textbook we use contains sixty units, which are very useful, because the examples are very practical and not too long. The book has a key to all the exercises and an index which lists all the collocations we deal with and indicates the units where they can be found. The teacher says that the textbook is ideal for both self-study and classroom use. In the classroom, we are asked to practice speaking out the collocations as quickly as we can. The teacher uses the repeated reading method to improve our reading speed and speaking fluency. We are requested to count the words we read a passage within one minute as in-class activity. We have never done this before, so we are very nervous and shy at the beginning. Of course, we perform awfully in the first few weeks. But after several weeks, we are used to this training. We have to practice not only in the classroom but also off-class. The teacher wants us to observe our own improvement through continuous practice (interviewees: Dora, Cindy, Mary, Alex). The participants in group 1 and group 2 unanimously agree that collocation instruction is very important in English learning. In the 30-minute interview, they seem to point out their shared problem: lack of collocation concept. None of the participants in this study has ever used a collocation dictionary Published by SCHOLINK INC. 
and/or language database. One of the most important objectives of this research is to train the students to apply the language database to their language learning. The researcher introduces to the participants a variety of databases available. For example, the researcher shows the participants how to judge an acceptable lexical collocation with the help of the BBI Dictionary of English Word Combinations, Oxford Collocations Dictionary for Learners of English, and online corpora like American National Corpus, Simple Search of British National Corpus, Collins Wordbanks Online, and Corpus of Contemporary American English. The researcher uses Corpus of Contemporary American English as sample to introduce the participants the entire entry procedures (See Appendix A). Prior to the researcher's instruction, all the participants have no idea about the language database, and they have no confidence in judging whether a collocation is acceptable or not. To reduce the learners' anxiety, the researcher makes an instruction card in which the student can follow the operational steps. Steps on the instruction card exemplify the procedures of accessing into the language database. One of the most important teaching strategies is to teach the students to use concordance, suggested by Koosha and Jafarpour (2006), which is defined as a method of analyzing language by studying structures and lexical patterns found in digital database. Concordances help students to confirm their utterance or writing is acceptable. In the present study, the researcher directs the participants to use corpus. Before that, the researcher will explain to the participants: (1) what is corpus? (2) what is concordance? (3) what is concordancing? Since the participants never use the database before, they need to practice step by step. Through group discussion, the participants can work together and find the problems among themselves. Regarding the efficiency of using corpus, the participants in group 3 and group 4 express their favorable attitudes.

Group 3: If we don't take the course, we will not know those useful learning resources. The teacher introduces several online language database to us, and also show us the way to access to the data. In our learning experience, the most used resource is English-Chinese dictionary or electric dictionary. The main purpose of checking the dictionary is to find the Chinese meaning of the English word we don't understand. We never use online language database before, because no one ever teaches us in the classroom. Fortunately, the teacher demonstrates us one of the online language databases. From the database, Corpus of Contemporary American English, we learn the way to search for the phrases or collocations we need. At the very beginning, we find it hard to use due to our unfamiliarity with the procedures to access to the database. Actually, the tool provides plentiful information from different resources. It seems to be complex and difficult for us due to our low English level. After practicing repeatedly with our classmates, we feel more comfortable and confident about how to use the powerful tool. The teacher says that acceptable or unacceptable production is one of the differentiate criteria between native and non-native speakers. Although we can communicate with foreigners, we don't know how to make sure whether our utterances are correct or not. With the assistance of online language database, we seem to be able to develop our language skills when the teacher is not present. Because we are not good at English, we depend heavily on the help of the teacher. But, if we can gain control of 
the know-how of concordancing, we think that we will become more confident language learners (interviewees: Stephanie, Susan, Emma, Max).

Group 4: The use of concordance is very helpful to us. The problem is that we are not very familiar with the procedures, and the huge amount of its output information seems to confuse us. To tell the truth, we seldom use English-English dictionary. The reason is simple: there are too many new English words appear after we look up in the dictionary. For example, if we check the meaning of the word "abacus" in the English-English dictionary, the definition will be "a wooden frame with sliding beads used for doing arithmetic". For higher level learners, the definition will be easier for them to understand. But, it is difficult for us since we are not good at English. The situation is the same when we are asked to do concordancing exercise. We feel frustrated when we start to learn about the application of concordance or corpus. Fortunately, the teacher encourages us to work harder in a very friendly and helpful way. The interaction with the teacher seems to reduce our anxiety during the learning process. The teacher says that if we learn well about concordancing and corpus, we may not depend on others when we want to say something or write something more correctly in the future. We are very happy to learn this skill, and hope to become more successful language learners (interviewees: Brenda, Jane, Laura, Peter).

Based on the feedback from the participants in Group 3 and Group 4, we realize that they show positive attitudes toward the teaching of corpus in the classroom. Concordances reveal not only word meaning and functions in general, but also extraordinary range of information about the language, such as the lexical, syntactic, semantic, and cultural information. Stevens (1995) points out that data-driven learning tool can support the development of learners' inductive learning habits, and promote language learners' responsibility for their own learning. In general, concordancing has immediate effects on the participants' ability to identify (mis)collocations. In the present research, all the participants express that online database is beneficial for their English learning. However, none of them ever received teacher's in-class support in using concordancing tool as learning resources before the research was conducted. The findings in this study reveal that the participants show very positive attitudes toward the instruction of using online language database in the teaching and/or learning a foreign language in the classroom. The result is consistent with previous studies that have found positive effects of concordancing as support for language learning (Chambers, 2005; Chan \& Liou, 2005; Chang \& Sun, 2009; Sun \& Wang, 2003). The change from deductive to inductive approach has led to the change of the teacher's and the learners' roles in the classroom. The teacher has become a coordinator and/or a facilitator, who helps the learners to deal with authentic language and foster their independence as a language learner. The concept of temporary assistance from the teacher has been referred to 'scaffolding', which can be viewed as a way of supporting the learners to perform a task, but this type of support is temporary. Once the learners can perform the assigned task independently, the help from the teacher is withdrawn. In the present study, the participants are divided into five small groups and they have to complete the assigned task through peer discussion, group cooperation, and peer Published by SCHOLINK INC. 
correction. The participants in group 5 express that they enjoy learning in a small group, because they feel more comfortable to discuss with their peers. In addition, they also mention they become more confident in language learning.

Group 5: We like to discuss with our classmates in the classroom. It is more fun, because we can talk freely and not worry about anything. We are nervous when we have to speak in front of other people. We are not good at expressing ourselves, because we don't have many chances to practice speaking with foreigners due to our low level of English proficiency. In this course, we have to practice speaking out aloud and quickly. The repeated reading method is new to us, but after several weeks, we find out that it is very useful. When we practice with classmates, we work together, and discuss freely. We are not so nervous compared to when we talk to the teacher. In the practice process, we start to care about fluency and accuracy. The textbook is good for us to practice, because the sentence in the book is not too long. We first translate the English collocation into Chinese, and then vice versa. The way enables us to automatically speak out the collocation. Then, by using the collocation, we have to make a sentence either mimic from the textbook or use our own imagination. For instance, we will use "fast food" and "quick meal" to create a conversation between us. It is useful for us to know the usage of these two words, or collocation. We often make mistakes in the past, but we don't know we have made mistakes. Now, we have better understanding about collocation because we have been taught the access to corpus, and so we will pay more attention to the words we use. Although it is still very hard for us to use the tool, we think that practice makes perfect, through continuous practice, we think that we will make improvement in our English proficiency(interviewees: Linda, Sarah, Howard, Michael).

The participants in group 5 point out that they prefer discussing with their classmates to the teacher. They express that they are less anxious when they are in a more comfortable learning environment. Tallon (2009) points out that one of the most important affective variables in learning a foreign language is foreign language anxiety. Crookall and Oxford (1991) assert that serious language anxiety adversely affect students' self-esteem, self-confidence, and ultimately hamper proficiency in language acquisition. Horwitz et al. (1986) indicate that communication apprehension, test anxiety, and fear of negative evaluation are three common types of anxiety. There are numerous anxiety-provoking sources in the classroom, such as speaking activities, negative classroom experience, native speaker, a harsh teaching manner, etc. To motivate the students, the teacher should create an atmosphere of mutual trust in the classroom. Classrooms are not only places where students learn, they are also places where teachers can learn. In the present study, the researcher adopts group work to increase the interaction among the participants. Repeated reading method inspires each participant to reduce speaking anxiety, because they repeatedly practice with their classmates in the classroom. CLT puts the focus on the learner. The role of the teacher is that of a facilitator, advisor, and co-communicator. The role of the students is to communicate by participating in meaning-negotiation activities and to manage their own learning. Although some of the participants are very anxious when assigned to speak in class, they show positive attitudes and strong motivation to practice English. The interaction between the teacher 
and the students plays a very important role in the teaching and learning process. Thanks to the size of the class, the researcher could interview each participant and understand their learning problems. Scaffolding is indispensable for the students during their learning process. However, the ultimate goal of education is to make the students become autonomous and independent learners.

\section{Pedagogical Suggestions}

Although the participants show favorable attitudes toward using online concordancing tool, some of them express their concerns. For example, the participants point out that it is difficult for them to select the right keyword, and there are huge amount of related information in concordance outputs. This derives mainly from the participants' low level of English proficiency as well as their lack of collocation concept. It is the teacher's duty to explain to the students about their problems, and help them to find the solution. The researcher recommends that to develop students into reflective, autonomous learners of English, teachers should integrate learning strategy instruction into communicative-oriented curricula and make necessary instructional adaptations after considering students' English proficiency levels. Lewis (2000) claims that collocation is mostly a matter of noticing and recording. In other words, the students should be taught how to find, record, and learn collocations. One of the ways of directing learners' attention to formal aspects of language is visual input enhancement, whose techniques such as underlining, bolding, highlighting have been used to increase the perceptual salience of the target forms. For example: I don't have access to that kind of vital information. Or: Mary gave me a very useful piece of advice. Learning collocations is not so different from learning any vocabulary item. The key things to remind the learners are: regularly revise what they want to learn, practice using what they want to learn in contexts that are meaningful for them personally. Learning collocation in groups will help the students to fix in their minds. One way is to group together collocations based on the same word, or to do so relating to the same topic. For example: Her symptoms included abdominal pain and vomiting. Are you in pain? These tablets should help to ease the pain. She was in constant pain. Output task is as important as input process. The word output is used to refer to the outcome of the language acquisition process. Swain and Lapkin (2002) point out that while learners attempt to produce the target language, they will recognize consciously some of their linguistic problems and bring their attention to what they need to solve their linguistic deficiency. In the present research, the task of the learners is output what they have learned in each unit by using the repeated reading method. Since the size of the class is small, only 20 members, it is ideal for the students to practice with each other. The output task has become an important factor to promote L2 learning. In a small class, the students' productive improvement in fluency and accuracy can be carefully monitored. Access to databases with huge authentic texts can really empower today's learners. For the self-study purpose, concordancing should be treated as a permanent task for the students in their long-term development of collocation knowledge. 


\section{Limitation}

This action research attempts to understand lower-level learners' perceptions toward collocation teaching and the effect on their language performance. Despite the research findings described above, the case study is not without limitation. In the study, the researcher uses a relatively small convenient sample, thus the generalizability of these participants' perceptions to other populations with different educational settings or backgrounds may be limited.

\section{Conclusion}

Collocation is one of the most problematic areas for foreign language learning. It is seemingly insurmountable obstacle to the attainment of native-like fluency. According to the statistical analysis, interviews, and observation, the researcher discovers that the participants hold positive attitudes toward the teaching and learning of collocations in the classroom. The participants express that they become more confident, compared to their previous learning experience. It is also evident that concordancing can be regarded as a co-supporter in helping learners eventually become autonomous language learners. The development of technology has made it possible for learners to explore corpora of authentic language and obtain samples of texts from these corpora with a concondancer. Collocation knowledge is fundamental for both receptive and productive use of the language to L2 learners, regardless of their language level. Preparing the learners to use collocations effectively and appropriately will contribute to efficient communication, which is the goal of learning a foreign language.

\section{Reference}

Ajzen, I. (2005). Attitudes, Personality and Behaviour (2nd ed.). Milton Keynes, UK: Open University Press.

Bahns, J. (1993). Lexical collocations: A contrastive view. ELT Journal, 47(1). 56-63.

Bahns, J., \& Eldaw, M. (1993). Should we teach EFL students collocation? System, 21(1), 101-114.

Benson, M., Benson, E., \& Ilson, R. (1986). The BBI combinatory dictionary of English: A guide to word combinations. Amsterdam: John Benjamin Publishing Company.

Bolinger, D., \& Sears, D. A. (1981). Aspects of language (pp. 87-88). New York: Jarcourt Brace Jovanovich, Inc.

Carter, R., \& McCarthy, M. (1988). Vocabulary and language teaching (pp. 68-75). New York: Longman.

Chambers, A. (2005). Integrating corpus consultation in language studies. Language Learning and Technology, 9(2), 111-125.

Chan, T. P., \& Liou, H. C. (2005). Effects of web-based concordancing instruction on EFL students' learning of verb-noun collocations. Computer Assisted Language Learning, 18(3), 231-251.

Chang, W., \& Sun, Y. (2009). Scaffolding and web concordancers as support for language learning. Computer Assisted Language Learning, 22(4), 283-330. 
Cowie, A. (1992). Multiword lexical units and communicative language teaching. In P. Arnaud, \& J. Bejoint (Eds.), Vocabulary and applied linguistics (pp. 216-331). London: Macmillan Academic and Professional LTD.

Crookall, D., \& Oxford, R. (1991). Dealing with anxiety: Some practical activities for language learners and teacher trainees. In E. K. Horwitz, \& D. J. Young (Eds.), Language Anxiety: From theory and research to classroom implications (pp. 141-148). Englewood Cliffs, NJ: Prentice Hall.

Decarrico, J. S. (2001). Vocabulary Learning and Teaching. In M. Celce-Murcia (Ed.), Teaching English as a Second or Foreign Language (pp. 285-299). Boston: Heinle \& Heinle.

Diller, D. (2007). Making the most of small groups: Differentiation for all. Ontario: Pembroke Publishers.

Dornei, Z. (2007). Research methods in applied linguistics. Oxford: Oxford University Press.

Dowhower, S. (1987). Effects of repeated reading on second-grade transitional readers fluency and comprehension. Reading Research Quarterly, 22, 389-406.

Ellis, N. C. (2001). Memory for language. In P. Robinson (Ed.), Cognition and second language instruction (pp. 33-68). Cambridge: Cambridge University Press.

Ferrance, E. (2000). Action Research. LAB: A Program of the Education Alliance at Brown University (pp. 1-33). Providence, RT: Brown University.

Firth, J. R. (1957). Modes of meaning. In J. R. Firth (Ed.), Papers in linguistics 1934-1951 (pp. 190-215). Oxford: Oxford University Press.

Hill, J. (2000). Revising priorities: From grammatical failure to collocational success. In M. Lewis (Ed.), Teaching collocation: further development in the lexical approach (pp.49-60). London: Language Teaching Publications.

Horwitz, E. K., Horwitz, M., \& Cope, J. (1986). Foreign languag classroom anxiety. The Modern Language Journal, 70(2), 125-132.

Johns, T. (1991). Should you be persuaded: Two samples of data-driven learning. English Language Research Journal, 4, 1-13.

Koosha, M., \& Jafarpour, A. A. (2006). Data-driven Learning and Teaching collocation of prepositions: The Case of Iranian EFL Adult Learners. Asian EFL Journal, 8(8), 23-32.

Koya, T. (2006). What is the reality of collocation use by native speakers of English? Dialogue, 5, $1-18$.

LaBerge, D., \& Samuels, S. J. (1974). Toward a theory of automatic information processing in reading. Cognitive Psychology, 6, 293-323.

Lewis, M. (1997). Implementing the lexical approach (pp. 34-44). England: Language Teaching Publication.

Lewis, M. (2000). Teaching collocation: Further developments in the lexical approach. London: Language Teaching Publications.

Liu, C. P. (2000a). A study of strategy use in producing lexical collocations. In Selected Papers from Published by SCHOLINK INC. 
the tenth International Symposium on English Teaching (pp. 481-492). Taipei: Crane.

McCarthy, M. J. (2004a, August). Collocation in vocabulary teaching and learning. Lecture given at the meeting of JACET summer seminar program, Gunma, Japan.

McIntosh, C., \& Francis, B. (2009). Oxford Collocations Dictionary for students of English (2nd ed.). Oxford University Press.

Nation, I. S. P. (2001). Learning vocabulary in another language. Cambridge: Cambridge University Press.

Nattinger, J. R., \& DeCarrico, J. S. (1992). Lexical phrase and language teaching. Oxford: Oxford University Press.

Nunan, D. (1988). The Learner-Centered Curriculum. Cambridge: Cambridge University Press.

Samuels, S. J. (1979). The method of repeated readings. The Reading Teacher, 32, 403-408.

Stevens, V. (1995). Concordancing with language learners: Why? When? What? CAELL Journal, 6(2), $2-10$.

Sun, Y. C., \& Wang, L. Y. (2003). Concordancers in the EFL classroom: Cognitive approaches and collocation difficulty. Computer Assisted Language Learning, 16(1), 83-95.

Swain, M., \& Lapkin, S. (2002). Talking it through: Two French immersion learners' response to reformulation. International Journal of Educational Research, 37, 285-304.

Tallon, M. (2009). Foreign Language Anxiety and Heritage students of Spanish: A Quantitative Study. Foreign Language Annals, 42(1), 112-137.

Tsai, A. S. (1995). An empirical study of collocation teaching. In Proceedings of the seventeenth conference on English Teaching and Learning in the Republic of China (pp. 165-178). Taipei: Crane.

Ur, P. (1996). A Course in Language Teaching: Practice and Theory. Cambridge: Cambridge University Press.

Wouden, T. V. (1997). Negative contexts: Collection, polarity, and multiple negation. New York: Routledge.

Young, A. R., \& Bowers, P. (1995). Individual differences and text difficulty determinants of reading fluency and expressiveness. Journal of Experimental Child Psychology, 60, 428-454.

\section{Appendix A: Introduction to the Corpus of Contemporary American English}

The Corpus of Contemporary American English (COCA) is the largest freely-available corpus of English, and the only large and balanced corpus of American English. The corpus was created by Mark Davies of Brigham Young University, and it is used by tens of thousands of users every month (linguists, teachers, translators, and other researchers). COCA is also related to other large corpora that we have created. The corpus contains more than $\mathbf{4 5 0}$ million words of text and is equally divided among spoken, fiction, popular magazines, newspapers, and academic texts. It includes 20 million words each year from 1990-2012 and the corpus is also updated regularly (the most recent Published by SCHOLINK INC. 
texts are from Summer 2012). Because of its design, it is perhaps the only corpus of English that is suitable for looking at current, ongoing changes in the language (see the 2011 article in Literary and Linguistic Computing). The interface allows you to search for exact words or phrases, wildcards, lemmas, part of speech, or any combinations of these. You can search for surrounding words (collocates) within a ten-word window (e.g. all nouns somewhere near faint, all adjectives near woman, or all verbs near feelings), which often gives you good insight into the meaning and use of a word. The corpus also allows you to easily limit searches by frequency and compare the frequency of words, phrases, and grammatical constructions, in at least two main ways: By genre: comparisons between spoken, fiction, popular magazines, newspaper, and academic, or even between sub-genres (or domains), such as movie scripts, sports magazines, newspaper editorial, or scientific journals. Over time: compare different year from 1990 to the present time. You can also easily carry out semantically-based queries of the corpus. For example, you can contrast and compare the collocates of two related words (little/small, democrats/republicans, men/women), to determine the difference in meaning or use between these words. You can find the frequency and distribution of synonyms for nearly 60,000 words and also compare their frequency in different genres, and also use these word lists as part of other queries. Finally, you can easily create your own lists of semantically-related words, and then use them directly as part of the query. Please feel free to take a five minute guided tour, which will show the major features of the corpus. A simple click for each query will automatically fill in the form for you, search through the more than 450 million words of text, and then display the results. The following links provide a good overview of the features of the corpus. Each link inputs values into the search interface and runs the query against the 450 million word corpus (i.e. these are not "canned" results). You might want to note which options have been selected in the form, and then modify the values to create your own queries. Using the web interface, you can search by words (mysterious), phrases (nooks and crannies or faint + noun), lemmas (all forms of words, like sing or tall), wildcards (un*ly or $\mathrm{r}$ ? $\mathrm{n}^{*}$ ), and more complex searches such as un-X-ed adjectives or verb + any word + a form of ground. Notice that from the "frequency results" window you can click on the word or phrase to see it in context in this lower window. As the preceding searches indicate, the first option in the search form allows you to either see a list of all matching strings, or a chart display that shows the frequency in the five "macro" registers (spoken, fiction, popular magazines, newspapers, and academic journals). Look for the frequency of funky, whom, incredibly + adjective, or forms of need + to + VERB. Via the chart display, you can also see the frequency of the word or phrase in sub-registers as well, such as movie scripts, children's fiction, women's magazines, or medical journals. With the list display, you can also see the frequency of each matching string in each of the major sections of the corpus (look for deep + noun, with and without the totals for each section).You can also search for collocates (words nearby a given word), which often provides insight into the meaning of a given word. For example, you can search for the most common nouns near thick, adjectives near smile (or sorted by relevance), nouns after look into, or words starting with clos* near Published by SCHOLINK INC. 
eyes.You can also include information about genre or a specific time period directly as part of the query. This allows you to see how words and phrases vary across speech and many different types of written texts. We can easily find which words and phrases occur much more frequently in one register than another, such as good + [noun] in fiction, or verbs in the slot [we * that] in academic writing. You can also apply this to collocates, such as nouns with the verb break in NEWS or adjectives with woman in FICTION. Finally, you can compare one section to another, such as nouns near chair in (ACAD vs FICTION), nouns with passionate (FICTION vs NEWSPAPER), verbs in magazines about religion compared to other magazines, or adjectives in medical journals compared to other journals. Finally, you can easily carry out semantically-oriented searches. For example, you can compare nouns that appear with small and little, with men and women, nouns with utter and sheer, adjectives with Democrats and Republicans (notice any bias here?), or verbs with Clinton and Bush (or emphases there?). You can also find the frequency and distribution of synonyms of a given word, such as beautiful or the verb clean, see which synonyms are more frequent in competing registers (such as synonyms of strong in FICTION and ACADEMIC), and use synonyms as part of a more complex query (such as synonyms of clean with nouns). Finally, you can create "customized lists" for any category that interests you, and then re-use these in subsequent queries (such as colors + clothes, or words related to beautiful + forms of woman). Hopefully this short five minute overview of the corpus has been helpful. Now feel free to look at more examples of the types of possible searches, including word/phrase, collocates (surrounding words), synonyms, word comparisons, and customized/user-defined lists. Find also more info on how to search by section (genre or year), and how to refine your searches with certain search options. (data taken from http://corpus.byu.edu/coca)

\section{Appendix B: Examples of test items on collocation}

\section{Part A:}

Please decide the underlined word combination in the following sentences is a collocation or not by putting C (collocation) or M (mis-collocation) in the blank

For example: There are some antique monument nearby. (Key: $\mathrm{M}$, ancient monument)

Part B:

Please choose the right word and put it in the blank

For example:

The storm did/made some damage to our roof. (Key: did)

Part C:

Please change the underlined words so that each sentence has the opposite meaning For example: It was scorching hot here yesterday. (Key: freezing cold) 


\section{Part D:}

Please choose the answer that best completes the following sentences

For example:

They are (a) happy (b) happily (c) happiness married. (Key: b) 